\title{
PENYULUHAN NAPZA PADA KARANGTARUNA SEBAGAI UPAYA PENCEGAHAN PENYALAHGUNAAN OBAT
}

\author{
Evicenna Naftuchah Riani ${ }^{1)}$, Wilis Dwi Pangesti1) \\ 1)Program Studi Kebidanan, Fakultas IImu Kesehatan, Universitas Muhammadiyah Purwokerto, Jawa Tengah, Indonesia \\ Corresponding author : Evicenna Naftuchah Riani \\ E-mail : evicenna@gmail.com
}

Diterima 12 Oktober 2020, Direvisi 31 Oktober 2020, Disetujui 02 November 2020

\begin{abstract}
ABSTRAK
Penyalahgunaan narkoba menjadi permasalahan mendesak di Indonesia. Narkotika, alcohol, psikotropika dan zat adiktif lainnya atau yang biasa dikenal dengan sebutan NAPZA merupakan benda terlarang dan sangat berbahaya bagi penggunanya dimana benda ini sudah menjadi trend dikalangan anak muda atau remaja. Hasil survei BNN menyebutkan 4 dari 100 orang pelajar/mahasiswa pernah menggunakan narkoba. Sebanyak 32 juta jiwa warga Jawa Tengah, terdapat 1,3\% atau sekitar 195 ribu jiwa warga Jawa Tengah adalah penyalah guna Narkoba. Menurutnya, angka prevalensi ini lebih tinggi jika dibandingkan dengan Provinsi lain seperti Jawa Barat yang hanya sebesar 0,8\%. Korban penyalahgunaan NAPZA di Kabupaten Purbalingga berjumlah 197 kasus. Berbagai upaya penangulangan terus dilakukan, namun karena tingginya mobilitas penduduk antar wilayah menyebabkan meningkatnya penyalahgunaan NAPZA. Pada tahun 2019 di Purbalingga ditemukan 32 kasus baru yang ditangani oleh BNN Kabupaten Purbalingga, dengan rincian 4 orang perempuan dan 28 orang laki-laki. Dengan rentang umur 14-41 tahun. Hasil akhir dari kegiatan ini diharapkan dapat memberikan manfaat pada mitra untuk memiliki pengetahuan NAPZA dan dapat meningkatkan kesadaran remaja untuk menjauhi narkoba. Metode yang digunakan dengan ceramah, diskusi, tanya jawab dan evaluasi kegiatan. Terdapat peningkatan pengetahuan tantang NAPZA pada karangtaruna Desa Talagening sebagai upaya dalam pencegahan penyalahgunaan obat-obatan yang dapat merusak kesehatan fisik dan jiwa.
\end{abstract}

Kata Kunci: penyuluhan; NAPZA; karangtaruna; pencegahan penyalahgunaan obat.

\begin{abstract}
Drug abuse is an urgent problem in Indonesia. Narcotics, alcohol, psychotropic substances and other addictive substances or commonly known as drugs are prohibited objects and are very dangerous for users where these objects have become a trend among young people or teenagers. The results of the BNN survey stated that 4 out of 100 students have used drugs. As many as 32 million people in Central Java, there are $1.3 \%$ or around 195 thousand people of Central Java who are drug abusers. According to him, this prevalence rate is higher when compared to other provinces such as West Java which is only $0.8 \%$. The number of victims of drug abuse in Purbalingga Regency is 197 cases. Various countermeasures have been carried out, however due to the high mobility of the population between regions it has led to increased drug abuse. In 2019 in Purbalingga, 32 new cases were found handled by the Purbalingga District National Narcotics Agency, with details of 4 women and 28 men. With an age range of 14-41 years. The end result of this activity is expected to provide benefits for partners to have knowledge of drugs and to increase awareness of adolescents to stay away from drugs. The method used is lectures, discussions, questions and answers and evaluation of activities. There is an increase in knowledge about drugs in the Talagening Village organization as an effort to prevent drug abuse that can damage physical and mental health.
\end{abstract}

Keywords: counseling; drugs; Karangtaruna; prevention of drug abuse.

\section{PENDAHULUAN}

Penyalahgunaan narkoba menjadi permasalahan mendesak di Indonesia. Narkotika, alkohol, psikotropika dan zat adiktif lainnya atau yang biasa dikenal dengan sebutan NAPZA merupakan benda terlarang dan sangat berbahaya bagi penggunanya dimana benda ini

sudah menjadi trend dikalangan anak muda atau remaja (Riani et al., 2016). Bukan hanya di kota besar tapi juga sudah masuk kepelosok desa seluruh Indonesia. Hasil survei BNN menyebutkan 4 dari 100 orang 
pelajar/mahasiswa pernah menggunakan narkoba (Putri, n.d.) (Nur'artavia, 2017).

Menurut WHO pengguna NAPZA di dunia mencapai 190 juta orang. Sementara pengguna NAPZA di Indonesia cenderung mengalami peningkatan dari tahun ketahun (Sinta Rachmawati, Sri Suryawati, 2018). Data BNN menyebutkan juga rata-rata 50 orang meninggal karena narkoba setiap harinya yang berarti sekitar 18.000 orang setiap tahunnya dan menurut hasil survey BNN mendapatkan temuan bahwa $24 \%$ pengguna NAPZA adalah remaja. Menurut data survei dari BNN pusat dengan angka prevalensi 2,2 atau mencapai 53,177 jiwa penggunanya(Kementerian Kesehatan RI, 2014).

Sebanyak 32 juta jiwa warga Jawa Tengah, terdapat 1,3\% atau sekitar 195 ribu jiwa warga Jawa Tengah adalah penyalah guna Narkoba. Angka prevalensi tersebut lebih tinggi jika dibandingkan dengan Provinsi lain seperti Jawa Barat yang hanya sebesar 0,8\%. (Firdaus \& Hidayati, 2018). Korban penyalahgunaan NAPZA di Kabupaten Purbalingga berjumlah 197 kasus. Berbagai upaya penangulangan terus dilakukan, namun karena tingginya mobilitas penduduk antar wilayah menyebabkan meningkatnya penyalahgunaan

NAPZA(Kemenkes RI, 2017).

Pada tahun 2019 di Purbalingga ditemukan 32 kasus baru yang ditangani oleh BNN Kabupaten Purbalingga, dengan rincian 4 orang perempuan dan 28 orang laki-laki. Dengan rentang umur 14-41 tahun. Latarbelakang pengguna narkoba yaitu 4 orang sebagai pelajar, 7 msebagi mahasiswa, 16 pekerja swasta dan 5 belum/ tidak pekerja. Sebanyak 32 kasus tersebut semuanya ditangani dan direhabilitasi oleh BNN. Langkah BNN Kabupaten Purbalingga dalam upaya Program Pencegahan dan Pemberantasan Penyalahgunaan Peredaran Gelap Narkoba (P4GN) dengan membentuk klinik pratama.(Purbalingga, 2020)

Angka kejadian remaja mengoplos obat obatan di Desa Talagening dengan minuman keras agar mereka bisa "ngefly" ditemukan sebanyak 10 kasus. Didesa Talagening ditemukan beberapa geng anak punk "geng" yang sangat meresahkan masyarakat. Keberadaan "geng" tersebut memiliki beberapa perilaku yang tidak baik. Diantara meminum minuman keras, penyalahgunaan obat dan merokok. Penyalahgunaan obat terungkap dengan adanya kejadian remaja yang meminum komix lebih dari 5 bungkus dalam sekali minum, mereka menyebutnya 'ngomix'. Selain minum komix , remaja juga minum dextro dan tramadol.

Hasi dari indepth interview didapatkan remaja desa talagening mengenal dextro dan tramadol sejak Sekolah Menengah Pertama
(SMP). Mereka mendapatkan obat tersebut dengan mudahnya. Beberapa remaja mendapatkannya dengan cara membeli atau diberi oleh tema sekolahnya. Tujuan remaja meminum obat-obatan tersebut supaya bisa ngefly. Dengan ngefly mereka seolah memiliki dunia lain yang bebas tidak terganggu oelh siapapun. Mereka meminum oabat-obatan tersebut diluar sepengetahuan orangtua. Selain angka penyalahgunaan obat di desa Talagening, sebanyak $65 \%$ remaja laki - laki merokok dan menimbulkan dampak buruk bagi lingkungan sekitar karena anak anak sekolah dasar di desa Talagening mengcopy perilaku kebiasaan merokok pada remaja di desa tersebut.

Tujuan diberikan penyuluhan pada mitra agar remaja mampu memahami NAPZA dan dapat menghindari untuk mengkonsumsinya serta menurunkan angka kejadian penyalahgunaan konsumsi obat. Sehingga remaja dapat hidup dengan sehat. Karena remaja yang sehat merupakan remaja yang bebas dari narkoba.

\section{METODE}

Kegiatan dilaksanakan di aula Desa Talagening kecamatan Bobotsari Kabupaten Purbalingga Provinsi Jawa tengah. Mitra merupakan kelompok karangtaruna Desa Talagening yang berjumlah 35 peserta. Metode yang disampaikan dengan learning by doing. Transfer kegiatan melalui penyuluhan dan pelatihan menggunakan media leaflet, power point, audio visual (video). Metode yang digunakan meliputi ceramah, tanya jawab, diskusi dan penayangan video. Tahapan kegiatan dimulai dengan icebraking, pretest, penyampaian materi, dan ditutup dengan posttest.

Evaluasi kegiatan dilakukan untuk mengukur tingkat keberhasilan dari program yang ditawarkan, yang meliputi evaluasi pengetahuan dan pemahaman sasaran pemahaman (knowledge) dilakukan dengan cara pretest dan posttest kepada seluruh peserta (Riani \& Ambarwati, 2020).

\section{HASIL DAN PEMBAHASAN \\ Penyuluhan NAPZA}

Penyuluhan NAPZA pada karangtaruna desa Talagening yang bertempat di aula balai desa. Peserta berjumlah 35 orang yang terdiri dari anggota karangtaruna. Media yang digunakan dalam penyuluhan berupa leaflet dan materi dalam bentuk power point.

Selama pemberian materi berlangsung, peserta aktif berpartisipasi dan bertanya hal-hal yang tidak dipahami. Diskusi dan tanya jawab didampingi oleh Tim pengabdian.

Selama pemberian materi berlangsung, peserta aktif berpartisipasi dan bertanya hal-hal 
yang tidak dipahami. Diskusi dan tanya jawab dilakukan. Proses diskusi membahas berbagai hal yang berkaitan dengan NAPZA. Kegiatan ini diakhiri dengan pemberian posttest sebagai hasil evaluasi pemberian penyuluhan.

Kegiatan penyuluhan NAPZA terdiri dari tahapan sebagai berikut:

a. Pretest

Kegiatan ini dilaksanakan dengan tujuan untuk mengetahui kemampuan peserta sebelum mengikuti kegiatan. Peserta diberikan soal terkait NAPZA. Alokasi waktu yang diberikan adalah 15 menit. Nilai peserta yang didapatkan rata-rata 67.

b. Penyampaian Materi

Materi yang disampaikan terdiri dari materi NAPZA. Alokasi waktu yang diberikan adalah 2 kali 30 menit dan dilanjutkan dengan diskusi tanya jawab.

c. Posttest

Posttest dilaksanakan di akhir kegiatan untuk mengetahui kemampuan peserta di akhir kegiatan. Hasil posttest menunjukan adanya peningkatan pengetahuan peserta dengan nilai rata rata 67 menjadi 94,5 atau terjadi peningkatan sebesar $40 \%$.

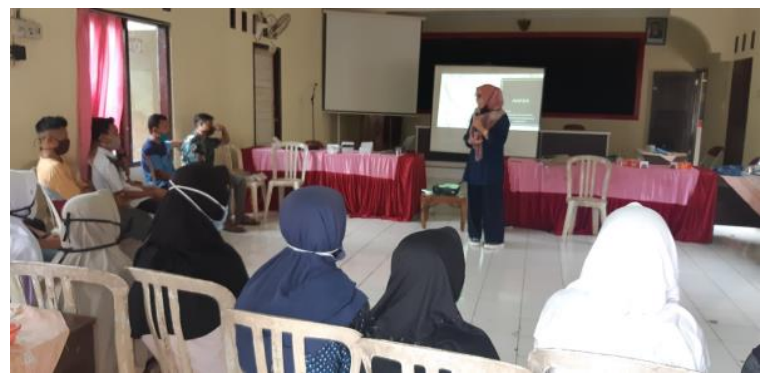

SIMPULAN

Terdapat peningkatan pengetahuan tantang NAPZA pada karangtaruna Desa Talagening sebagai upaya dalam pencegahan penyalahgunaan obat-obatan yang dapat merusak kesehatan fisik dan jiwa.

Karantaruna Desa Talagening akan ikut berperan aktif dalam kegiatan desa guna menurunkan angka kejadian penyalahgunaan obat-obatan.

\section{DAFTAR RUJUKAN}

Firdaus, A. M. yunanta, \& Hidayati, E. (2018). Pengetahuan Dan Sikap Remaja Terhadap Penggunaan Napza Di Sekolah Menengah Atas Di Kota Semarang. Jurnal Keperawatan Jiwa, 6(1), 1-7. https://doi.org/10.26714/jkj.6.1.2018.1-7

Kemenkes RI. (2017). Infodatin Pusat Data dan Informasi Kementrian Kesehatan Anti Narkoba Sedunia 26 Juni 2017. In Anti Narkoba Sedunia 26 Juni 2017.

Kementerian Kesehatan RI. (2014). Buletin
Jendela Data Dan Informasi Kesehatan. http://www.ghbook.ir/index.php?name=مجمون عهد مقالات دومين هم انديشى سراسرى رسانه تلويزيون و \&كو لاريسم ne\&book_id=13629\&page=108\&chkhashk= 03C $706812 \mathrm{~F} \&$ ltemid $=218 \&$ lang $=$ fa\& $\mathrm{tmpl}=\mathrm{C}$ omponent

Nur'artavia, M. R. (2017). Karakteristik Pelajar Penyalahguna Napza Dan Jenis Napza Yang Digunakan Di Kota Surabaya. The Indonesian Journal of Public Health, 12(1), 27.

https://doi.org/10.20473/ijph.v12i1.2017.2738

Purbalingga, D. K. K. (2020). Profil Kesehatan Kabupaten Purbalingga Tahun 2019.

Putri, M. D. I. R. H. F. E. (n.d.). PENINGKATAN PENGETAHUAN REMAJA TENTANG BAHAYA AKIBAT NARKOTIKA, ALKOHOL, PSIKOTROPIKA DAN ZAT ADIKTIF LAIN (NAPZA) DI SMA N 15 KABUPATEN MUARO JAMBI.

Riani, E. N., \& Ambarwati, D. (2020). Early Detection Kanker Serviks Sebagai Upaya Peningkatan Derajat Hidup Perempuan. SELAPARANG Jurnal Pengabdian Masyarakat Berkemajuan, 3(2), 144. https://doi.org/10.31764/jpmb.v3i2.1883

Riani, E. N., Shaluhiyah, Z., \& Widagdo, L. (2016). Petugas Lapangan Sebagai Ujung Tombak Jumlah Pengunjung Klinik VCT. Jurnal Promosi Kesehatan Indonesia; Volume 9, No. 2, Agustus 2014DO 10.14710/Jpki.9.2.152-161

https://ejournal.undip.ac.id/index.php/jpki/ar ticle/view/12730

Sinta Rachmawati, Sri Suryawati, R. (2018). Efektivitas CBIA-Narkoba dalam Peningkatan Pengetahuan Remaja untuk Menolak Narkoba Effectiveness of CBIADrug in Improving Youth Knowledge to Resist Drugs. Jurnal MKMI, 14(4), 339-344. https://doi.org/http://dx.doi.org/10.30597/mk mi.v14i4.4477 